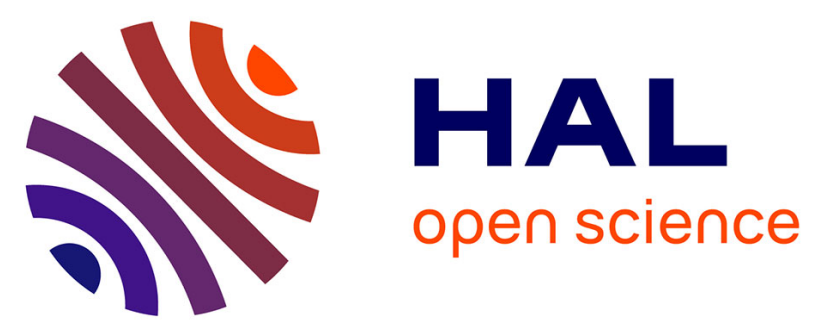

\title{
Activation of the aryl hydrocarbon receptor by carcinogenic aromatic amines and modulatory effects of their N-acetylated metabolites
}

Ludmila Juricek, Linh-Chi Bui, Florent Busi, Stéphane Pierre, Erwan Guyot, Aazdine Lamouri, Jean-Marie Dupret, Robert Barouki, Xavier Coumoul, Fernando Rodrigues-Lima

\section{To cite this version:}

Ludmila Juricek, Linh-Chi Bui, Florent Busi, Stéphane Pierre, Erwan Guyot, et al.. Activation of the aryl hydrocarbon receptor by carcinogenic aromatic amines and modulatory effects of their N-acetylated metabolites. Archives of Toxicology, 2014, 89 (12), pp.2403-2412. 10.1007/s00204-0141367-7 . hal-02195701

\author{
HAL Id: hal-02195701 \\ https://hal.science/hal-02195701
}

Submitted on 26 Jul 2019

HAL is a multi-disciplinary open access archive for the deposit and dissemination of scientific research documents, whether they are published or not. The documents may come from teaching and research institutions in France or abroad, or from public or private research centers.
L'archive ouverte pluridisciplinaire HAL, est destinée au dépôt et à la diffusion de documents scientifiques de niveau recherche, publiés ou non, émanant des établissements d'enseignement et de recherche français ou étrangers, des laboratoires publics ou privés. 


\section{Activation of the Aryl Hydrocarbon Receptor by Carcinogenic Aromatic Amines and Modulatory Effects of their $N$-Acetylated Metabolites}

Ludmila Juricek ${ }^{*},, 1$, Linh-Chi Bui ${ }^{\sharp, 1}$, Florent Busi ${ }^{\star}$, Stéphane Pierre ${ }^{*}$, , Erwan Guyot ${ }^{*},{ }^{*}$, Aazdine Lamouri ${ }^{\S}$, Jean-Marie Dupret ${ }^{\ddagger}$, Robert Barouki ${ }^{* \dagger,}$, Xavier Coumoul ${ }^{*, \dagger, 2}$, Fernando Rodrigues-Lima ${ }^{\ddagger}$

* INSERM UMR-S 1124, Toxicologie Pharmacologie et Signalisation cellulaire, 45 rue des Saints-Pères, 75006 Paris, France

${ }^{\dagger}$ Université Paris Descartes, Sorbonne Paris Cité, 45 rue des Saints-Pères, 75006 Paris, France

$¥$ Université Paris Diderot, Sorbonne Paris Cité, CNRS EAC 4413, Biologie Fonctionnelle et Adaptative, 4 rue Marie-Andrée Lagroua Weill Hallé, 75213 Paris, France

${ }^{\S}$ Université Paris Diderot, Sorbonne Paris Cité, Laboratoire ITODYS, CNRS UMR 7086, 15, rue Jean-Antoine de Baïf, 75013, Paris, France

I AP-HP, Hôpital Necker-Enfants Malades, Service de biochimie métabolique, 149 rue de Sèvres, 75743 Paris, France

${ }^{1}$ Equal contribution; ${ }^{2}$ Share senior autorship

To whom correspondence should be addressed at INSERM UMR-S 1124, 45 rue des SaintsPères, 75006 Paris, France, fax : +33142863868 ; email : $\underline{\text { xavier.coumoul@ parisdescartes.fr }}$ and CNRS EAC 4413, 4 rue Marie-Andrée Lagroua Weill Hallé, 75213 Paris, France, fax : +33157278329 ; email : fernando.rodrigues-lima@univ-paris-diderot.fr

Running title: Effect of AA $N$-acetylation on AhR activation 


\begin{abstract}
Aromatic amines (AAs) are an important class of chemicals which account for $12 \%$ of known carcinogens. The biological effects of AAs depend mainly on their biotransformation into reactive metabolites or into $\mathrm{N}$-acetylated metabolites which are generally considered as less toxic. Although the activation of the Aryl Hydrocarbon Receptor (AhR) pathway by certain carcinogenic AAs has been reported, the effects of their $N$-acetylated metabolites on the AhR have not been addressed.
\end{abstract}

Here, we investigated whether carcinogenic AAs and their $N$-acetylated metabolites may activate/modulate the AhR pathway in the absence and/or the presence of a bonafide AhR ligand (Benzo[a]pyrene/B(a)P). In agreement with previous studies, we found that certain AAs activated the AhR in human liver and lung cells as assessed by an increase in cytochrome P450 1A1 (CYP1A1) expression and activity. Altogether, we report for the first time that these properties can be modulated by the $\mathrm{N}$-acetylation status of the AA. Whereas $2-$ naphtylamine (2-NA) significantly activated the AhR and induced CYP1A1 expression, its $\mathrm{N}$ acetylated metabolite was less efficient. In contrast, the $\mathrm{N}$-acetylated metabolite of 2aminofluorene was able to significantly activate AhR whereas the parent AA, 2aminofluorene (2-AF), did not. In the presence of $\mathrm{B}(\mathrm{a}) \mathrm{P}$, activation of $\mathrm{AhR}$ or antagonist effects were observed depending on the AA or its $\mathrm{N}$-acetylated metabolite.

Activation and/or modulation of the AhR pathway by AAs and their $N$-acetylated metabolites may represent a novel mechanism contributing to the toxicological effects of AAs. More broadly, our data suggest biological interactions between AAs and other classes of xenobiotics through the AhR pathway.

Keywords: acetylation, aromatic amines, aryl hydrocarbon receptor, benzo(a)pyrene, metabolism, mixture 


\section{Introduction}

Aromatic amines (AAs) are widely present in the environment and they account for approximately $12 \%$ of the chemicals that are known or are strongly suspected to be carcinogenic in humans (National Toxicology Program 2011). Human epidemiological studies have shown that occupational exposure to AAs, including 2-naphthylamine (2-NA) and 4-aminobiphenyl (4-ABP), is associated primarily with an increased incidence of urinary bladder cancer (Talaska, 2003). Exposure to AAs still occurs in many industries, including rubber, dyestuffs and textile manufacturing, and coal/pesticides and pharmaceutical productions (Ferraz et al. 2012; Freeman 2013). AAs are present also in diesel-exhaust particles and cooking oil fumes. A major non-occupational source of exposure to AAs is tobacco smoke which also contains other carcinogenic molecules such as benzo(a)pyrene (B(a)P) (Turesky and Le Marchand 2011; Ferraz et al. 2012).

The molecular mechanism that is suggested to explain the etiology of AA exposureassociated cancers relies on the metabolic activation of AAs to reactive metabolites which target DNA and produce adducts (Kim and Guengerich 2005; Neumann 2010; Turesky and Le Marchand 2011). Indeed, the metabolism of AAs is often regarded as a balance between two major metabolic routes. On the one hand, the AA can undergo several $N$-conjugation reactions among which $\mathrm{N}$-acetylation by the arylamine $N$-acetyltransferases (NAT) plays a major role. This $\mathrm{N}$-acetylation reaction is described as a detoxification reaction since it decreases the reactivity of the primary amine function and leads, in general, to poorly "toxic" or even "innocous" metabolites (Hein et al. 2000; Kim and Guengerich 2005; Turesky and Le Marchand 2011). On the other hand, the AA can be converted to arylhydroxylamines primarily as a result of reactions catalyzed by the cytochrome P450 monooxygenase (CYP1) family, in particular CYP1A2 in the liver (Kim and Guengerich 2005). Following $N$ oxidation, the aromatic amine metabolite can be $O$-acetylated by NAT enzymes to give a 
highly reactive nitrenium ion. This electrophilic ion reacts with DNA to form covalent adducts which may elude the repair systems and cause mispairing during replication which thus leads to the initiation of carcinogenesis (Rodrigues-Lima et al. 2008).

The AhR is a ligand-activated transcription factor which belongs to the basic-helixloop-helix/Per-ARNT-Sim (PAS) family and regulates the response to many xenobiotics (Fukunaga et al. 1995; Abel and Haarmann-Stemmann 2010). The AhR is a critical mediator of gene-environment interactions. This receptor is involved in the transcriptional induction of the genes coding the CYP1 enzymes by compounds from two major categories of molecules: polycyclic aromatic hydrocarbons (PAH, such as $\mathrm{B}(\mathrm{a}) \mathrm{P})$ and dioxin and dioxin-like molecules (such as 2,3,7,8-tetrachlorodibenzo-p-dioxin). In brief, after ligand activation, the AhR is translocated to the nucleus where it heterodimerizes with the AhR nuclear translocator (ARNT). The heterodimer binds to a xenobiotic response element (XRE) located in the promoter region of target genes and recruits the transcriptional machinery (Barouki et al. 2007).

Certain aromatic amides ( $N$-acetyl-AA) such as 2-acetylaminofluorene (2-AAF) and 2-acetylaminophenanthrene (2-AAP) have been reported to bind to the rat AhR (Cikryt et al. 1990). Interestingly, a higher induction of CYPlA genes was observed (Borza et al. 2008) when porcine urinary bladder epithelial cells (PUBEC) were co-exposed to $\mathrm{B}(\mathrm{a}) \mathrm{P}$ in combination with 4-ABP or 2-NA (as compared to B(a)P). However, these AAs did not induce the expression of CYP1A in the absence of B(a)P. In addition, some AhR target genes, including CYP1A1 and CYP1A2, are strongly regulated in response to acute and chronic exposure to heterocyclic aromatic amines (HAA) (Dumont et al. 2010).

In the present study, we showed that certain carcinogenic AAs activate the AhR signaling pathway in the presence or the absence of a bonafide AhR ligand (B(a)P) in both human liver and lung cells. More importantly, we demonstrate that this activation depends on 
the $N$-acetylation status of the AA. In particular, we found that in contrast to its parent molecule (2-AF), the $N$-acetylated metabolite (2-AAF) was able to activate the AhR pathway. However, in the case of 2-NA, its $N$-acetylated metabolite (2-ANA) activated the AhR less than the parent AA compound. Neither 4-ABP nor its $N$-acetylated metabolite were able to activate the AhR. Exposure of cells to AAs or their $N$-acetylated metabolites in the presence of $\mathrm{B}(\mathrm{a}) \mathrm{P}$ led to various effects, depending upon the AA and the $N$-acetylated metabolite tested.

Our findings suggest that the biological effects of certain AAs depend, at least in part, upon the activation and/or the modulation of the AhR pathway by the parent AA or its $\mathrm{N}$ acetylated metabolite. Consequently, the effect of an AA upon the AhR pathway is also likely to depend on its biotransformation by xenobiotic-metabolizing enzymes. In turn, the activation of the AhR by some AAs and/or their $N$-acetylated metabolites is likely to impact the metabolism and the toxicological fate of AAs (as well as other aromatic chemicals such as PAH) through AhR-dependent up/down regulation of CYP1A enzymes. Our results, therefore, point to a new dynamic model for the metabolism and biological impact of AAs. More broadly, our study provides a better understanding of the mechanisms that could contribute to the biological effects of AA carcinogens and suggest that biological/toxicological interactions occur between AAs and other classes of xenobiotics through the AhR pathway. 


\section{Methods}

\section{Chemicals and cells}

Aromatic amines (2-AF, 2-NA and 4-ABP), N-acetylated 2-AF (2-AFA), benzo[a]pyrene (B(a)P) and $\mathrm{CH}-223191$ were obtained from Sigma-Aldrich. $N$-acetylated 2NA (2-ANA) and $\mathrm{N}$-acetylated 4-ABP (4-AABP) were synthesized as previously described (Martins et al. 2009). All stock solutions of chemicals were prepared in DMSO.

The human liver cell line, HepG2, and the human lung epithelial cell line, NCI-H292, were obtained from the American Type Cell Collection (ATCC). Cell culture media, Lipofectamine and G418 were from Invitrogen. Fetal bovine serum was from the Institut Jacques Boy or Invitrogen.

\section{Luciferase reporter gene construction}

The CYP1A1-XRE-GLuc vector was constructed from the pGLuc basic vector (New England Biolabs) after digestion with the restriction enzymes BglII and EcoRI (New England Biolabs,) and ligation with an oligonucleotide containing the consensus XRE derived from the CYP1A1 promoter and a TATA box (5'gggtcgcagcgcttctcacgcgagccgggactcagtaacctataaagctgcgG-3'). HepG2 cells were stably transfected with this plasmid. One day before transfection, the HepG2 cells $\left(1.5 \times 10^{6}\right.$ cells/10-cm dish) were seeded into the usual medium containing fetal bovine serum. The CYP1A1-XRE-GLuc vector $(2 \mu \mathrm{g})$ was introduced into the cells using Lipofectamine (Invitrogen) according to the manufacturer's recommendations. Twenty four hours later, the medium was replaced with fresh medium containing $2000 \mu \mathrm{g} / \mathrm{ml} \mathrm{G} 418$. The medium containing G418 was changed every 3 days. Three weeks later, the surviving cells were harvested and pooled for luciferase assay. The transfected cells (CYP1A1-XRE-Luc) were maintained in a medium containing $600 \mu \mathrm{g} / \mathrm{ml} \mathrm{G418.}$ 


\section{Cell culture and luciferase assays.}

Human hepatoblastoma HepG2 cells and human lung epithelial NCI-H292 cells were cultured in a humidified atmosphere in $5 \% \mathrm{CO}_{2}$ at $37^{\circ} \mathrm{C}$, in Dulbecco's minimal essential medium (DMEM) complemented with non essential amino acids, 10\% fetal bovine serum, 200U/mL penicillin, $50 \mu \mathrm{g} / \mathrm{mL}$ streptomycin and $0.5 \mu \mathrm{g} / \mathrm{mL}$ amphotericin B for the HepG2 cells and in RPMI medium supplemented with $1 \%$ Glutamax and $10 \%$ fetal calf serum for the NCI-H292 cells. The HepG2 stably-transfected cell line, with the reporter gene under the control of a xenobiotic responsive element, named CYP1A1-XRE-GLuc HepG2 cells (see above), was maintained in an identical fashion to the original cell line with an additional $0.6 \mathrm{mg} / \mathrm{mL}$ geneticin. For the Luciferase assays, $\mathrm{HepG} 2$ cells were seeded into 24-well plates $\left(8 \times 10^{4}\right.$ cells/well). Two days later, the medium was replaced and the cells were treated with the xenobiotics. Twenty-four hours later, $6 \mu \mathrm{L}$ of the supernatant were collected and deposited in 96-well microtiter plates. Then, $30 \mu \mathrm{L}$ of BioluxGaussia Luciferase Substrate (BioluxGaussia Luciferase Assay, New England Biolabs) were added immediately prior to luminescent measurements with a WallacEnVision 2101 Multilabel Reader (Perkin Elmer). Blanks were obtained by measuring the luciferase activity in the medium without cells.

For the dose-response study, cells were plated into 24 -well culture plates $\left(8 \times 10^{4}\right.$ cells/well, HepG2 cells) or 12 -well culture plates $\left(1 \times 10^{5}\right.$ cells/well, NCI-H292 cells). Two days later, the medium was replaced and cells were exposed to different concentrations of an AA or its $N$-acetylated metabolite for 24 hours.

For the time-course study, the cells were cultivated under the same conditions as for the dose-response studies and incubated with DMSO or $25 \mu \mathrm{M}$ of each AA or its $N$-acetylated metabolite for different times $(4 \mathrm{~h}, 8 \mathrm{~h}, 16 \mathrm{~h}, 24 \mathrm{~h}$ or $48 \mathrm{~h})$. For the experiments involving the AhR antagonist, the cells were pretreated with $\mathrm{CH} 223191$ for 1 hour $(3 \mu \mathrm{M}$ for $\mathrm{HepG} 2$ cells 
and $2.5 \mu \mathrm{M}$ for NCI-H292 cells), and then exposed to the AA or its $N$-acetylated metabolite for $8 \mathrm{~h}$ (HepG2 cells) or 24h (NCI-H292 cells).

\section{Cell viability assay (WST-1)}

Cells were seeded into 96 -well plates $\left(1 \times 10^{4}\right.$ cells/well). Two days later, the medium was replaced and cells were exposed to B(a)P and/or the aromatic amines for $24 \mathrm{~h}$. Then, the medium was withdrawn and a dilution of 1:10 WST-1 in complete DMEM medium was added for $2 \mathrm{~h}$ at $37^{\circ} \mathrm{C}$. Subsequently, optical densities were measured at $490 \mathrm{~nm}$ using a microplate reader (Safire, Tecan).

\section{RNA extraction and quantitative RT-PCR}

Total RNAs were extracted using the RNeasy mini kit (Qiagen) or using TriReagent (Euromedex) as described by the manufacturer and quantified with a spectrophotometer (ND1000 Nanodrop, Nanodrop products, Wilmington, DE, USA). Reverse transcription was performed using the cDNA high-capacity archive kit (Applied Biosystems) or the M MLV Reverse Transcriptase kit (Promega). Real-time quantitative PCR (qPCR) analysis was performed using the ABI PRISM 7900HT Sequence Detection System (Applied Biosystems) or Light Cycler 480 Thermo cycler (Roche Meylan, France). Gene-specific primers used for real-time PCR reactions were as follows: for the human CYP1A1 (forward 5'GACCACAACCACCAAGAAC-3' and reverse 5'-AGCGAAGAATAGGGATGAAG-3'); human AhR (forward 5'-ACATCACCTACGCCAGTCGC-3' and reverse 5'TCTATGCCGCTTGGAAGGAT-3'); for control human ubiquitin C (forward 5'CACTTGGTCCTGCGCTTGA-3' and reverse 5'-TTTTTTGGGAATGCAACAACTTT-3') and human RPL-19 (forward 5'-CAAGGTGTTTTTCCGGCATC-3 and reverse 5GGCTCGCCTCTAGTGTCCTC-3). 


\section{EROD activity}

The EROD activity in cultured cells was measured by the fluorescence of resorufin generated by the conversion of ethoxyresorufin by CYP1A1, CYP1A2, and CYP1B1 using a fluorescence plate reader (Coumoul et al. 2001).

\section{Statistical tests}

All the data are representative of at least three different experiments. The values are expressed as mean \pm sem. The data were analyzed by analysis of variance (ANOVA) followed by Fisher's LSD test to examine the differences between the different groups. A value of $\mathrm{p}<0.05$ was considered statistically significant. 


\section{Results}

Effects of AAs and their N-acetylated metabolites on AhR-dependent reporter gene expression in a CYP1A1-XRE-GLuc HepG2 cell line

We evaluated the effects of exposure to AAs (with or without B(a)P) on AhR activation in cells. We used three representative AAs and their $N$-acetylated metabolites: 2aminofluorene (2-AF) as an experimental carcinogenic AA, and 4-ABP and 2-NA, as two relevant carcinogenic AAs known to be present in tobacco smoke. The HepG2 cell line stably transfected with the CYP1A1-XRE-GLuc was exposed to these molecules with or without $\mathrm{B}(\mathrm{a}) \mathrm{P}$, a PAH chemical (also present in tobacco smoke) which is known to be a bonafide ligand and activator of AhR. The HepG2 cell line expresses the AhR at high levels and is frequently used to study the influence of putative AhR ligands on the expression of xenobiotic-metabolizing enzymes. These engineered cells represent useful tools for the identification of molecules that activate the AhR via a simple luciferase activity measurement.

Reporter gene expression, as measured by luciferase activity, was induced in a dosedependent manner following exposure of CYP1A1-XRE-GLuc HepG2 cells for 24h to 2-NA, 2-AAF and to 2-ANA in the absence of $\mathrm{B}(\mathrm{a}) \mathrm{P}$ (Figure 1). In contrast, 2-AF, 4-ABP and 4-AABP did not produce any significant luciferase activity in the absence of B(a)P. However, these molecules elicited an interesting dose dependent antagonism of B(a)P-triggered XRE activation, as was also the case with 2-ANA (for the highest doses of the aromatic amines) (Figure 1)_It is remarkable that the concentrations of AAs used did not produce significant toxicity under these experimental conditions as assessed by WST1 reduction except for 2-AF, 2-AAF, 4-ABP and 4-AABP for which a $20-30 \%$ decrease in cell viability was observed only at the highest concentration $(100 \mu \mathrm{M}$, Supp. table 1). Overall, this suggested that minor chemical modifications of AA dramatically affect their ability to trans-activate the expression of xenobiotic metabolism enzymes. Interestingly, the acetylating reaction affected the ability 
of aromatic amines to activate our reporter gene construct either positively or negatively. This indicated that the transcriptional mechanism involved in this regulation is complex and might be related to the plasticity of the AhR towards its ligands whose involvement in this process was tested next.

\section{Influence of exposure to cells to AAs on CYP1A1 mRNA expression}

The AA-dependent modulation of reporter gene induction in our engineered cell model presumably involves the AhR and the XRE. Therefore, we decided to measure the endogenous level of mRNA of CYP1A1, a well-characterized AhR cellular target the expression of which is increased upon ligand-dependent AhR activation. Human liver and human lung epithelial cells were chosen because the lung is a primary route of entry for AAs and the liver is a major site of AA biotransformation in humans. Moreover, the lungs and the liver are the important routes for the entry and biotransformation, respectively, of $\mathrm{B}(\mathrm{a}) \mathrm{P}$ as well. Finally, similar responses in two unrelated cell lines would strengthen the validity of a common underlying molecular mechanism.

CYP1A1-XRE-GLuc HepG2 (Figure 2A) and NCI-H292 (Figure 2B) cells treated with 2 -AAF and 2 -NA $(0.1 \mu \mathrm{M}$ to $100 \mu \mathrm{M})$ for $24 \mathrm{~h}$ show a strong dose-dependent induction of endogenous CYP1A1 mRNA as measured by quantitative real time PCR (qRT PCR). Overall, the results obtained with both cell lines (Figure 2) are consistent with the luciferase experiments. In contrast, 2-AF, 2-ANA, 4-ABP and 4-AABP were very poor inducers of CYP1Al gene expression and even the highest doses $(50$ and $100 \mu \mathrm{M})$ resulted only in low levels of induction in the CYP1A1-XRE-GLuc HepG2 cell line. In addition, the antagonism with $\mathrm{B}(\mathrm{a}) \mathrm{P}$ is concordant, in general, with the reporter gene assays although slight discrepancies were observed with both cell lines (Figure 2). As a control, and to rule out any artifacts due to the stable insertion of the plasmid bearing the luciferase reporter gene in 
CYP1A1-XRE-GLuc HepG2, we also conducted these experiments in the "wild-type" (non-

transfected) HepG2 cell line and obtained similar results (data not shown). We concluded that 2-acetylated aminofluorene (2-AAF) and non-acetylated 2-NA activated the AhR signaling pathway while 2-AF and 2-ANA are less active. Interestingly, all compounds appeared to inhibit the trans-activating effect of BaP at lower doses $(0.1 \mu \mathrm{M})$ in the CYP1A1-XRE-GLuc $\underline{\text { HepG2 cell line suggesting that } \mathrm{BaP} \text { and aromatic amines competed for the same binding site }}$ (of the AhR). This effect depended on the cell line and was not found in the NCI-H292 cells, $\underline{\text { suggesting this effect was tissue-dependent, probably related to different metabolisms. }}$

The time course of induction of CYP1A1 also was studied in both cell lines upon exposure to AAs or their $N$-acetylated metabolites at a concentration of $25 \mu \mathrm{M}$. In HepG2 cells, induction was observed as early as $4 \mathrm{~h}$, with a maximum at 8 hours, after treatment with 2-NA and 2-ANA, and was sustained for $48 \mathrm{~h}$ for 2-NA (Figure 3A). A similar trend was observed with NCI-H292 cells (Figure 3B). 2-AFA elicited an important increase (up to 70fold) of CYP1A1 mRNA at 4h. It is of note that, in the case of HepG2 cells, the inductions progressively declined after $8 \mathrm{~h}$ of exposure. $4-\mathrm{ABP}$ and its metabolites did not have any effect on CYP1A1 mRNA expression in HepG2 cells. However, a significant decrease of CYP1A1 mRNA was observed at 8,16 and $24 \mathrm{~h}$ of treatment with $4-\mathrm{AABP}$ and $16 \mathrm{~h}$ of treatment with 4 ABP in NCI-H292 cells. In the case of 2-AF, the results showed a steady although small increase of CYP1A1 mRNA for up to $48 \mathrm{~h}$ in HepG2 whereas 2-AF markedly decreases CYP1A1 mRNA in NCI-H292 cells (Figure 3). To confirm the results reported above, we also measured the EROD activity of the cells treated for $8 \mathrm{~h}$ with $25 \mu \mathrm{M}$ of the compounds. As expected, the levels of EROD activity were found to correlate with the induction of CYP1A1 after $8 \mathrm{~h}$ of treatment (Supplementary Figure 1).

\section{Involvement of the AhR signaling pathway following exposure to AAs}


To further demonstrate the involvement of the AhR in the induction of the CYPlAl gene following exposure of HepG2 and NCI-H292 cells to the AAs and their $\mathrm{N}$-acetylated metabolites, we investigated the effects of 2-NA and 2-ANA in the presence of $\mathrm{CH}-223191$. $\mathrm{CH}-223191$ is a potent and specific AhR antagonist, which does not display agonist activity even at high concentrations $(>100 \mu \mathrm{M})$. In addition, $\mathrm{CH}-223191$ displays no affinity for the estrogen receptor (Choi et al. 2012). $\mathrm{CH}-223191$ significantly impaired the ability of 2-NA and 2-ANA to induce CYP1A1 in both HepG2 and NCI-H292 cells (Figure 4). 


\section{Discussion}

A diversity of well-characterized toxic chemicals can be identified among AA compounds. Some of these are reported as carcinogens and, notably, are involved in the welldocumented etiology of certain cancers (in particular bladder cancer). It is thought that the molecular mechanism responsible for the genotoxicity of these molecules relies mainly on their metabolic activation as a result of both cytochrome P450-mediated $N$-hydroxylation (in particular those in the CYP1 family) followed by $O$-acetylation catalyzed by NAT enzymes. The unstable acetoxyester product is rapidly converted to an electrophilic nitrenium cation that forms DNA adducts. In addition to this bioactivation pathway, AAs can also undergo NAT catalyzed $\mathrm{N}$-acetylation. This reaction is considered as a detoxification pathway as it reduces their chemical reactivity.

Studies have reported that AAs can induce a variety of phase I enzymes, such as CYPI genes through the activation of AhR (Borza et al. 2008; Dumont et al. 2010). 2-NA and 4ABP have been shown to induce CYP1A1 in PUBEC cells (Borza et al. 2008). In addition, 2acetylaminofluorene (2-AAF) and 2-acetylaminophenanthrene (2-AAP) are capable of displacing TCDD from rat AhR showing that this AA metabolite can bind to the receptor with a high affinity (Cikryt et al. 1990). However, it is not clear whether all AA have similar effects and whether they behave as agonists or antagonists. Interestingly, these molecules correspond to acetylated derivatives of the aromatic primary amines 2-AF and 2aminophenanthrene (2-AP) (Cikryt et al. 1990). Therefore, considering these observations, we addressed the hypothesis that AA-mediated CYP1 induction, indeed, results from the activation of the AhR pathway by the acetylated AA metabolites (produced in vivo by NAT enzymes) rather than the parent AA. For this purpose, we performed experiments with three well-known AA (2-NA, 4-ABP and 2-AF) used in the studies by Borza et al. (2008) and Cikryt et al. (1990) as well as their $N$-acetylated forms (2-ANA, 4-AABP and 2-AAF) in 
order to distinguish the cellular effects of the AA from their acetylated metabolites. The acetylated AAs mimic the cellular NAT-mediated $N$-acetylation products. The HepG2 and NCI-H292 cell lines, which exhibit low NAT activities, permit the investigation of the true contribution of the primary amine versus the arylamide compounds. Our results are in agreement with previous studies (Cikryt et al. 1990; Borza et al. 2008; Dumont et al. 2010) and show that AAs can be regarded as activators of AhR pathway similarly to PAH or dioxinlike molecules. Indeed, all three AA / N-acetylated AA metabolite couples used here appear to differentially activate the AhR signaling pathway. This may be a more general feature of AAs since 3,4-dichloroaniline (3,4-DCA) and 4-iodoaniline (4-IA) also are able to alter luciferase reporter gene expression (data not shown) and $p$-phenylenediamine (PPD) has been reported to induce CYPIAl (Dr B.Blomeke, communication at the $5^{\text {th }}$ international workshop on the arylamine $N$-acetyltransferase, Paris 2010). The fact that subtle chemical modifications of AA dramatically affected their ability to trans-activate the AhR signaling pathway, might be $\underline{\text { related to the structural plasticity of the receptor. Indeed, we previously showed that different }}$ $\underline{\text { AhR ligands activated different genes due to differential binding to canonical or non- }}$ canonical XRE. For example, 2, 3, 7, 8-tetrachlorodibenzo-p-dioxin was able to promote the activation of the CYP1A1 gene transcription through AhR-binding to the classical XRE (GCGTG) while resveratrol and other related polyphenols promoted paraoxonase 1 gene expression through non-canonical XRE (GCGGG) binding of the AhR (Gouédard et al. 2003; Gouédard et al. 2004). Our hypothesis is that ligands might differentially change the whole structure of this receptor (plasticity) affecting its ability to bind responsive elements. Thus, acetylation of aromatic amines might switch the ability of the AhR to bind canonical XRE $\underline{\text { such as the ones found in our construct or endogenously, in the CYP1A1 gene, on or off. }}$

More importantly, our results show that the acetylation of AAs is a key modulator of their propensity to activate the AhR and that the activation of the AhR pathway differs from 
one AA to another. Although all these aromatic compounds belong to the same chemical family, they behave differently. For instance, although 2-NA appears to activate the AhR, its efficacy decreases once it is acetylated. In contrast, 2-AF becomes an activator after acetylation. Therefore, by extrapolation, in vivo acetylation might modulate the capacity of AAs to activate (or antagonize) the AhR pathway and induce (or repress) CYPl genes. Thus, exposure to these chemicals might reasonably alter the balance between NAT and CYP1 enzyme activities and possibly shift the metabolism towards bio-activation rather than $\mathrm{N}$ acetylation. This could be important since most exposures to AAs are chronic which probably negatively affect the metabolic outcome of the exposure to these chemicals in terms of DNA adduct production. Our results also underline the usefulness of assessing AA metabolism dynamically as a balance between NAT and CYP1 enzyme activities, which can evolve as a function of exposure to AAs as a result of activation of the AhR.

Exposure concomitantly to AAs and polycyclic aromatic hydrocarbons (PAH) occurs often as a function of occupation and lifestyle. For instance, both AAs (2-NA and 4-ABP) and $\mathrm{B}(\mathrm{a}) \mathrm{P}$ are found in cigarette smoke. Therefore, we tested the ability of each AA or each arylamide to alter AhR signaling when co-exposed with $\mathrm{B}(\mathrm{a}) \mathrm{P}$. Indeed, $\mathrm{B}(\mathrm{a}) \mathrm{P}$ is a strong inducer of the AhR gene battery. This carcinogen is activated to the highly reactive benzo[a]pyrene-7,8-dihydrodiol-9,10-epoxide by a metabolic pathway involving CYP1 and epoxide hydrolase enzymes (Xue and Warshawsky 2005). Therefore, in addition to the promotion of its own bioactivation, $\mathrm{B}(\mathrm{a}) \mathrm{P}$ may also promote the bioactivation of AAs by increasing CYPIA gene expression. In a co-exposure context, we show here that AAs and/or their $N$-acetylated forms can act with B(a)P to modulate CYP1A expression. More generally, this interaction likely depends upon the respective affinities and ratios of concentrations of AAs and PAHs in the mixture to which the cell is exposed. 
It is intriguing that Borza et al. (2008) observed a dramatic synergism in porcine bladder PUBEC cells, between 2-NA or 4-ABP and $\mathrm{B}(\mathrm{a}) \mathrm{P}$ in the induction of CYP1Al while each AA did not induce CYP1A1 alone. In our study, in NCI-H292 cells, 4-ABP and 4-AABP displayed inhibitory properties alone and 2-NA alone behaved as an agonist (Figure 3). Therefore, there is a discrepancy between these studies, which may be due to species-specific responses that involve variations in the amino acid sequences of the ligand binding domains of the receptors. However, it cannot be ruled out that this discrepancy results from tissue specificities. The study from Borza et al. (2008) was conducted in porcine bladder cells whereas our study employs human liver and lung cells.

In conclusion, our work shows that certain carcinogenic AAs are able to activate the $\mathrm{AhR}$ in the presence/or in the absence of $\mathrm{B}(\mathrm{a}) \mathrm{P}$ in human liver and lung cells, which is in agreement with studies carried out with other cell types. More importantly, we found, for the first time, that the $\mathrm{N}$-acetylation status of these AAs modulates this activation. For instance, whereas 2-NA was found to activate the AhR and to induce CYPlAl expression, its Nacetylated metabolite (2-ANA) was much less efficient. In contrast, the $\mathrm{N}$-acetylated metabolite of 2-AF (2-AFA) activated the AhR whereas the parent compound 2-AF did not. Moreover, in the presence of $\mathrm{B}(\mathrm{a}) \mathrm{P}$, agonist or antagonist effects were found which were dependent upon the AA or its $\mathrm{N}$-acetylated metabolite.

Our results strongly support the notion that the biological effects of certain AAs may be due, at least in part, to the activation/modulation of the AhR pathway by these AAs or their $\mathrm{N}$-acetylated metabolites. As a consequence, our data also suggest that the properties of AAs towards the AhR pathway depend on their metabolism. In turn, this activation of the AhR pathway by AAs may more broadly impact the metabolic and toxicological fate of AAs and other aromatic chemicals (such as $\mathrm{B}(\mathrm{a}) \mathrm{P}$, etc) through the regulation of the expression of CYP1A enzymes. 
Our data provide a new molecular and cellular mechanism that help to clarify the biological effects of AA carcinogens. More broadly, our work further supports possible biological/toxicological interactions between AA chemicals and other classes of xenobiotics through the AhR pathway. 


\section{Funding}

This work was supported by the Université Paris Descartes, Université Paris Diderot, INSERM (Institut National de la Santé et de la Recherche Médicale), the CNRS (Centre National de la Recherche Scientifique), the ANSES (Agence nationale de sécurité sanitaire de l'alimentation, de l'environnement et du travail, Funding), the Fondation pour la Recherche Médicale (Post doctoral fellowship, Linh-Chi Bui), the Ligue contre le Cancer (Postdoctoral fellowship, Linh-Chi Bui), the Assistance Publique-Hôpitaux de Paris (Erwan Guyot) and the Région Ile de France (PhD fellowships : Ludmila Juricek, Stéphane Pierre).

\section{Acknowledgments}

We thank Dr Lawrence Aggerbeck and Martin Cairns for his critical reading of this manuscript 


\section{References}

Abel J, Haarmann-Stemmann T (2010) An introduction to the molecular basics of aryl hydrocarbon receptor biology. Biol Chem 391:1235-1248. doi: 10.1515/BC.2010.128

Barouki R, Coumoul X, Fernandez-Salguero PM (2007) The aryl hydrocarbon receptor, more than a xenobiotic-interacting protein. FEBS Lett 581:3608-3615. doi: 10.1016/j.febslet.2007.03.046

Borza A, Plöttner S, Wolf A, et al. (2008) Synergism of aromatic amines and benzo[a]pyrene in induction of $\mathrm{Ah}$ receptor-dependent genes. Arch Toxicol 82:973-980. doi: $10.1007 / \mathrm{s} 00204-008-0381-\mathrm{z}$

Choi E-Y, Lee H, Dingle RWC, et al. (2012) Development of novel CH223191-based antagonists of the aryl hydrocarbon receptor. Mol Pharmacol 81:3-11. doi: 10.1124/mol.111.073643

Cikryt P, Kaiser T, Göttlicher M (1990) Binding of aromatic amines to the rat hepatic Ah receptor in vitro and in vivo and to the $8 \mathrm{~S}$ and $4 \mathrm{~S}$ estrogen receptor of rat uterus and rat liver. Environ Health Perspect 88:213-216.

Conso F (2004) [Occupational exposure and bladder cancer]. Rev Prat 54:1665-1670.

Coumoul X, Diry M, Robillot C, Barouki R (2001) Differential regulation of cytochrome P450 1A1 and 1B1 by a combination of dioxin and pesticides in the breast tumor cell line MCF-7. Cancer Res 61:3942-3948. 
Dumont J, Jossé R, Lambert C, et al. (2010) Preferential induction of the AhR gene battery in HepaRG cells after a single or repeated exposure to heterocyclic aromatic amines. Toxicol Appl Pharmacol 249:91-100. doi: 10.1016/j.taap.2010.08.027

Esser C (2012) Biology and function of the aryl hydrocarbon receptor: report of an international and interdisciplinary conference. Arch Toxicol. doi: 10.1007/s00204-012-0818-2

Ferraz ERA, de Oliveira GAR de, de Oliveira DP de (2012) The impact of aromatic amines on the environment: risks and damages. Front Biosci Elite Ed 4:914-923.

Freeman HS (2013) Aromatic amines: use in azo dye chemistry. Front Biosci J Virtual Libr 18:145-164.

Fukunaga BN, Probst MR, Reisz-Porszasz S, Hankinson O (1995) Identification of functional domains of the aryl hydrocarbon receptor. J Biol Chem 270:29270-29278.

Gorrod JW, Manson D (1986) The metabolism of aromatic amines. Xenobiotica Fate Foreign Compd Biol Syst 16:933-955. doi: 10.3109/00498258609038975

Gouédard C, Barouki R, Morel Y (2004) Dietary polyphenols increase paraoxonase 1 gene expression by an aryl hydrocarbon receptor-dependent mechanism. Mol Cell Biol 24:52095222. doi: 10.1128/MCB.24.12.5209-5222.2004

Gouédard C, Koum-Besson N, Barouki R, Morel Y (2003) Opposite regulation of the human paraoxonase-1 gene PON-1 by fenofibrate and statins. Mol Pharmacol 63:945-956.

Hein DW, McQueen CA, Grant DM, et al. (2000) Pharmacogenetics of the arylamine Nacetyltransferases: a symposium in honor of Wendell W. Weber. Drug Metab Dispos Biol Fate Chem 28:1425-1432. 
Kim D, Guengerich FP (2005) Cytochrome P450 activation of arylamines and heterocyclic amines. Annu Rev Pharmacol Toxicol 45:27-49. doi: 10.1146/annurev.pharmtox.45.120403.100010

Landi MT, Bertazzi PA, Shields PG, et al. (1994) Association between CYP1A1 genotype, mRNA expression and enzymatic activity in humans. Pharmacogenetics 4:242-246.

Martins M, Rodrigues-Lima F, Dairou J, et al. (2009) An acetyltransferase conferring tolerance to toxic aromatic amine chemicals: molecular and functional studies. J Biol Chem 284:18726-18733. doi: 10.1074/jbc.M109.015230

McMillan BJ, Bradfield CA (2007) The aryl hydrocarbon receptor sans xenobiotics: endogenous function in genetic model systems. Mol Pharmacol 72:487-498. doi: $10.1124 / \mathrm{mol} .107 .037259$

National Toxicology Program (2011) NTP 12th Report on Carcinogens. Rep Carcinog Carcinog Profiles US Dept Health Hum Serv Public Health Serv Natl Toxicol Program 12:iii499.

Neumann H-G (2010) Aromatic amines: mechanisms of carcinogenesis and implications for risk assessment. Front Biosci J Virtual Libr 15:1119-1130.

Palmiotto G, Pieraccini G, Moneti G, Dolara P (2001) Determination of the levels of aromatic amines in indoor and outdoor air in Italy. Chemosphere 43:355-361.

Rodrigues-Lima F, Dairou J, Dupret J-M (2008) Effect of environmental substances on the activity of arylamine N-acetyltransferases. Curr Drug Metab 9:505-509. 
Talaska G (2003) Aromatic amines and human urinary bladder cancer: exposure sources and epidemiology. J Environ Sci Health Part C Environ Carcinog Ecotoxicol Rev 21:29-43. doi: 10.1081/GNC-120021372

Turesky RJ (2002) Heterocyclic aromatic amine metabolism, DNA adduct formation, mutagenesis, and carcinogenesis. Drug Metab Rev 34:625-650. doi: 10.1081/DMR120005665

Turesky RJ, Le Marchand L (2011) Metabolism and biomarkers of heterocyclic aromatic amines in molecular epidemiology studies: lessons learned from aromatic amines. Chem Res Toxicol 24:1169-1214. doi: 10.1021/tx200135s

Turesky RJ, Vouros P (2004) Formation and analysis of heterocyclic aromatic amine-DNA adducts in vitro and in vivo. J Chromatogr B Analyt Technol Biomed Life Sci 802:155-166. doi: $10.1016 /$ j.jchromb.2003.10.053

Xue W, Warshawsky D (2005) Metabolic activation of polycyclic and heterocyclic aromatic hydrocarbons and DNA damage: a review. Toxicol Appl Pharmacol 206:73-93. doi: 10.1016/j.taap.2004.11.006 


\section{Figure legends}

Fig1. Effects of 2-AF, 2-NA, 4-ABP and their N-acetylated metabolites 2-AAF, 2-ANA, 4-AABP alone or in combination with $\mathbf{B}(\mathbf{a}) \mathbf{P}$ on luciferase activity. HepG2 cells were stably transfected with the XRE-controlled luciferase reporter gene (CYP1A1-XRE-GLuc HepG2 cells). Cells were treated with the indicated concentrations of aromatic amines and/or $1 \mu \mathrm{M} \mathrm{B}(\mathrm{a}) \mathrm{P}$ for $24 \mathrm{~h}$, and then luciferase activity was assayed. The results are expressed as ratios as compared to the control condition. The data are the means \pm SEM of three separate experiments, each conducted in triplicate.* statistically different from control group $(* \mathrm{p}<$ $0.05 ; * * \mathrm{p}<0.01 ; * * * \mathrm{p}<0.001)$. \# statistically different from $\mathrm{B}(\mathrm{a}) \mathrm{P} 1 \mu \mathrm{M}$ treated group $(\# \mathrm{p}<$ 0.05; \#\# $\mathrm{p}<0.01 ; \# \# \mathrm{p}<0.001)$.

Fig2. Relative transcript levels of CYP1A1 in CYP1A1-XRE-GLuc HepG2 (A) and NCIH292 (B) cells treated with 2-AF, 2-NA, 4-ABP or their metabolites 2-AAF, 2-ANA, 4AABP alone or in combination with B(a)P. mRNA were collected $24 \mathrm{~h}$ after exposure of cells to the compound(s)and then, the relative level of CYP1A1 mRNA was measured by qRT-PCR to establish a dose response curve. The data are the means \pm SEM of five separate experiments. ${ }^{*} \mathrm{p}<0.05 ; * * \mathrm{p}<0.01 ; * * * \mathrm{p}<0.001$ versus control and $\# \mathrm{p}<0.05$ versus $1 \mu \mathrm{M}$ $\mathrm{B}(\mathrm{a}) \mathrm{P}$ treated group.

Fig3. Time course of CYP1A1 mRNA expression. HepG2 (A) or NCI-H292 (B) cells were incubated with DMSO (control), 2-AF, 2-AAF, 2-NA, 2-ANA, 4-ABP or 4-AABP (25 $\mu \mathrm{M})$ for the indicated time points. CYP1A1 mRNA expression was measured by qRT-PCR in three independent experiments and the values are the mean \pm SEM. $* \mathrm{p}<0.05 ; * * \mathrm{p}<0.01 ; * * * \mathrm{p}<$ 0.001 
Fig4. Effects of $\mathrm{CH}-223191$, a pharmacological antagonist of AhR on the relative induction of CYP1A1 by AAs or their $N$-acetylated metabolites. Cells were pretreated with $3 \mu \mathrm{M} \mathrm{CH}-223191$ for 45 minutes, then AAs or their $N$-acetylated metabolites were added for $8 \mathrm{~h}$ prior to total RNA extraction and measurement of the relative induction of CYP1A1 by qRT-PCR. Values are the mean $\pm \operatorname{SEM}(\mathrm{n}=4) . * \mathrm{p}<0.05 ; * * \mathrm{p}<0.01$ and $* * * \mathrm{p}<0.001$ as compared to corresponding control group.

\section{Supplementary table 1: Measurement of the viability of CYP1A1-XRE-GLuc HepG2} cells following treatment with AAs and BaP. CYP1A1-XRE-GLuc HepG2 cells were seeded into $96-$-well plates $\left(0.01 \times 10^{6}\right.$ cells/well $)$. Two days later, the medium was replaced and cells were exposed to $\mathrm{B}(\mathrm{a}) \mathrm{P}$ and/or the aromatic amines for $24 \mathrm{~h}$. Then, the medium was withdrawn and a dilution of 1:10 WST-1 in complete DMEM medium was added for $2 \mathrm{~h}$ at $37^{\circ} \mathrm{C}$. Subsequently, optical densities were measured at $490 \mathrm{~nm}$ using a microplate reader (Safire, Tecan). The values are normalized to the control (DMSO). The data are the means \pm SEM of three separate experiments, each conducted in triplicate. No statistical difference was observed.

Supplementary figure 1: Measurement of the EROD activity of CYP1A1-XRE-GLuc HepG2 cells following treatment with AAs and BaP. Cells were treated for $8 \mathrm{~h}$ with $25 \mu \mathrm{M}$ of the compounds. EROD activity in cultured cells was measured by the fluorescence of resorufin generated by the conversion of ethoxyresorufin by CYP using a fluorescence plate reader (Coumoul $X$ et al. 2001). Values are the mean $\pm \operatorname{SEM}(n=4) . * p<0.05 ; * * p<0.01$ and $* * * \mathrm{p}<0.001$ as compared to corresponding control group. 

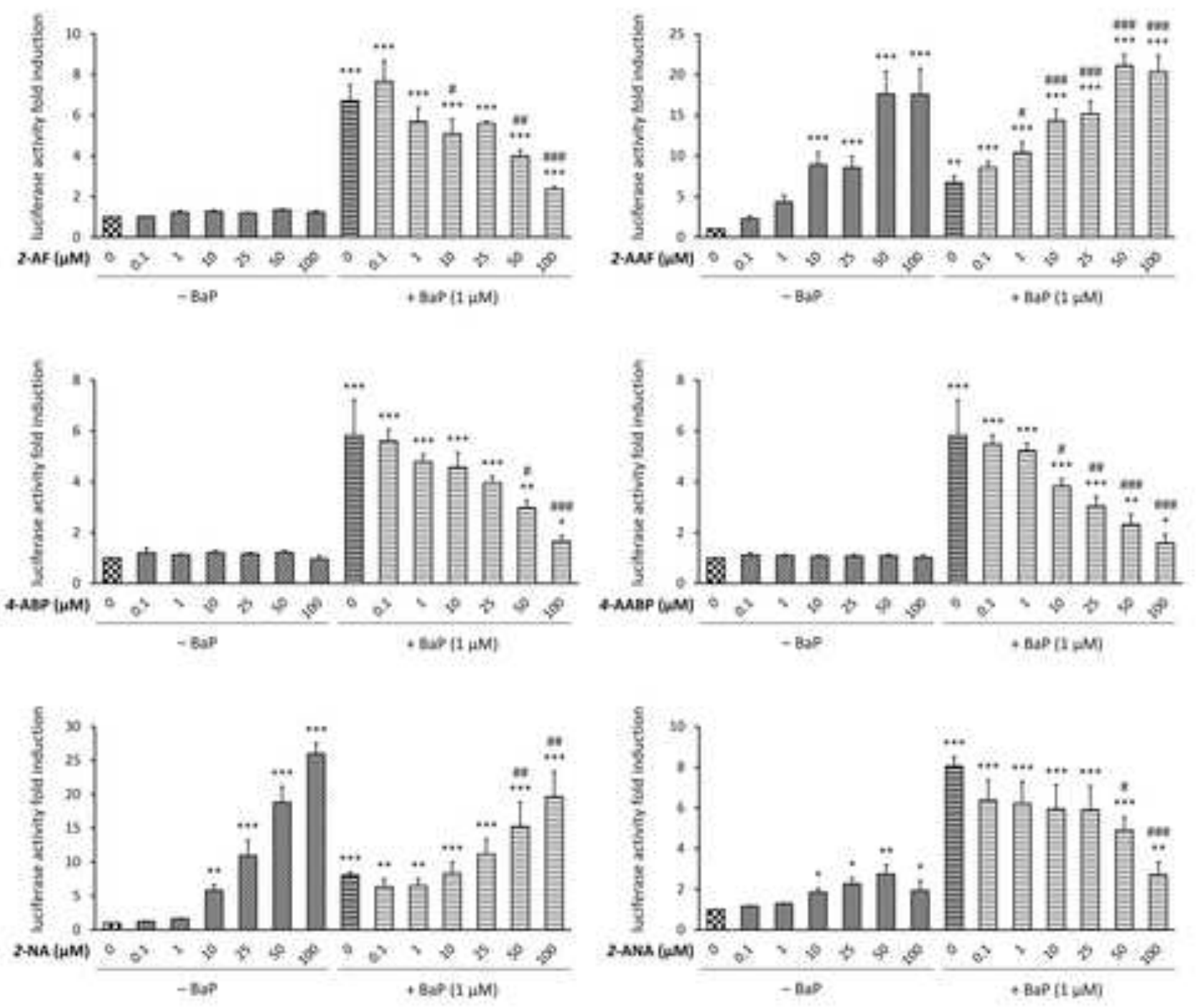

FIGURE 1 
(A)
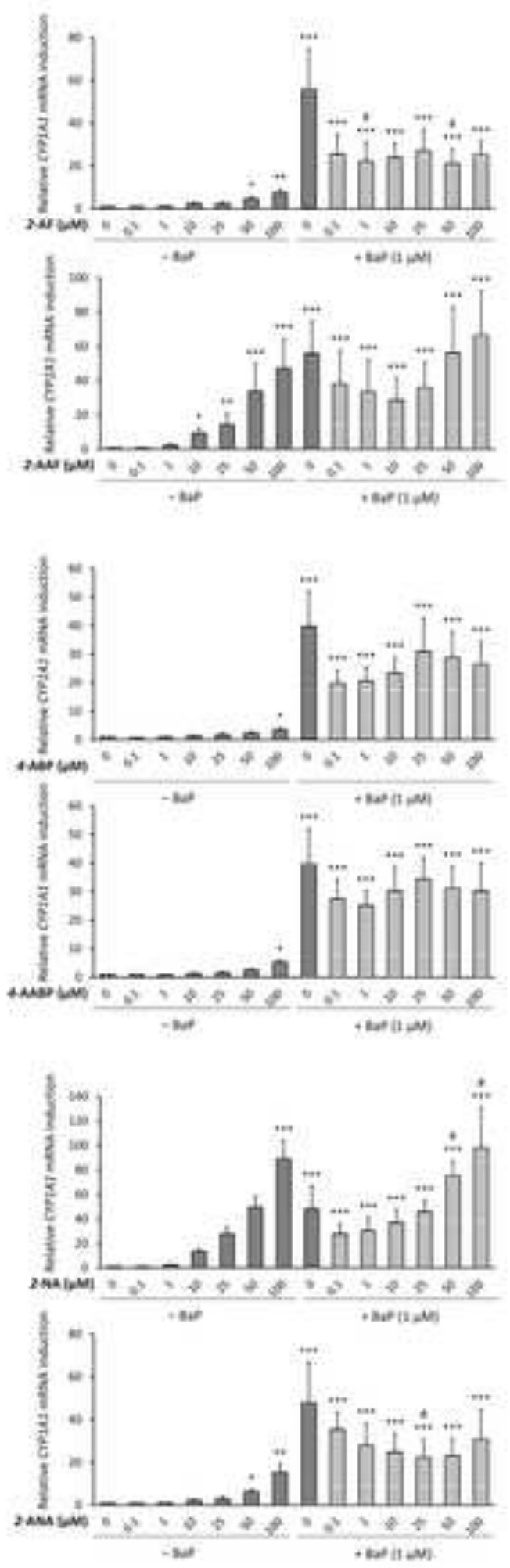

(B)
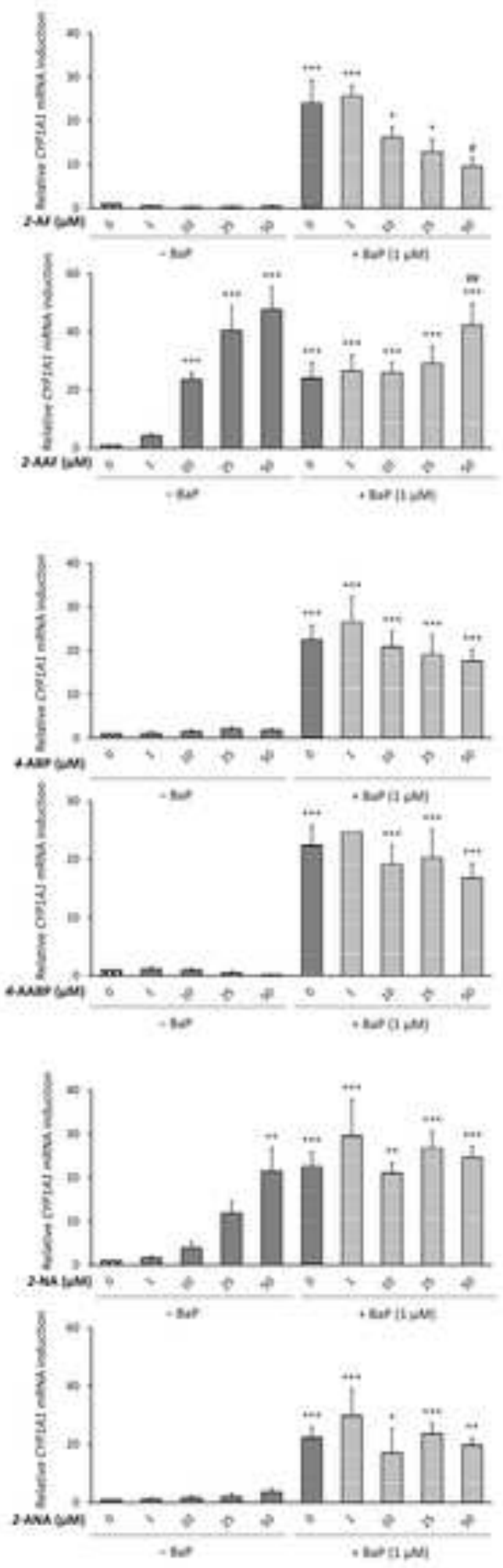
Figure 3

Click here to download high resolution image

(A)
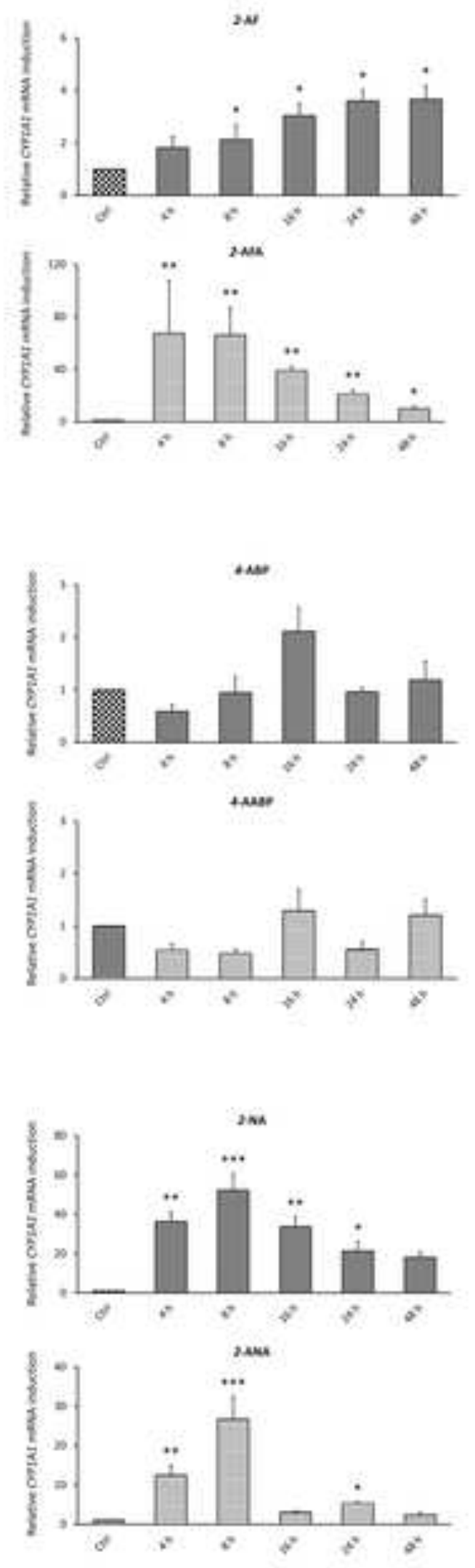

(B)
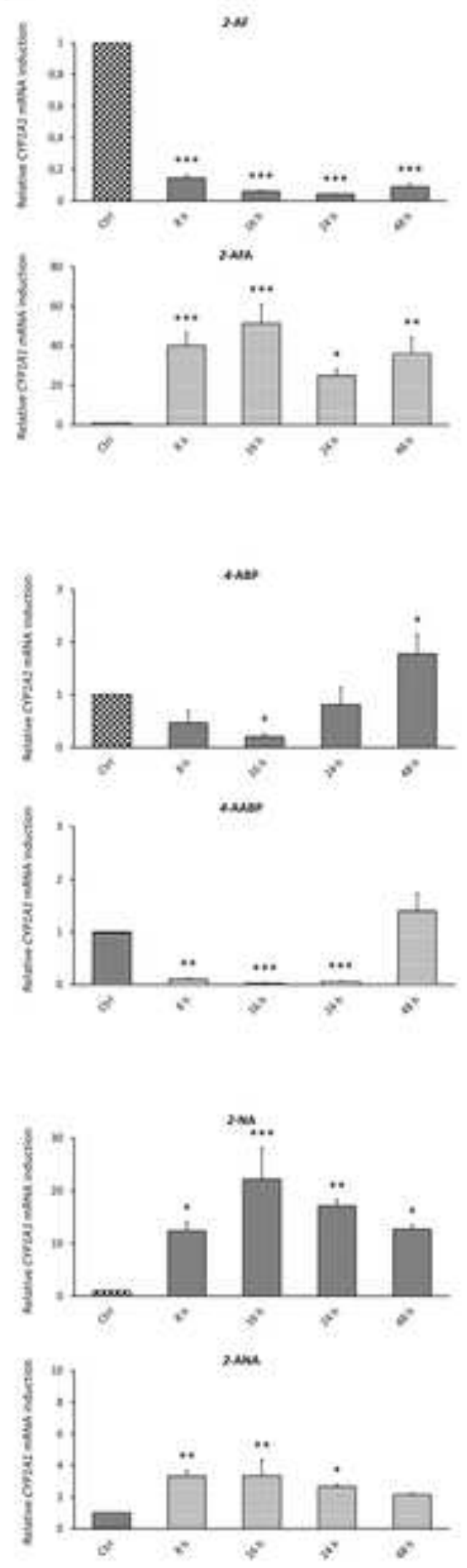
(A)

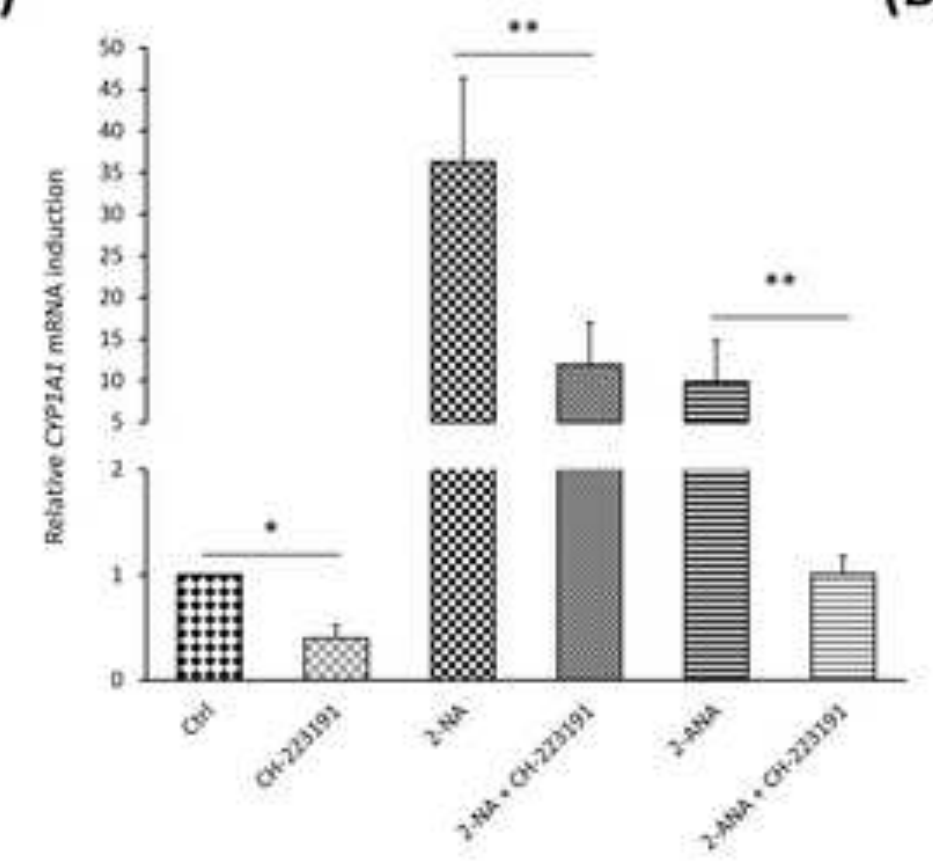

(B)

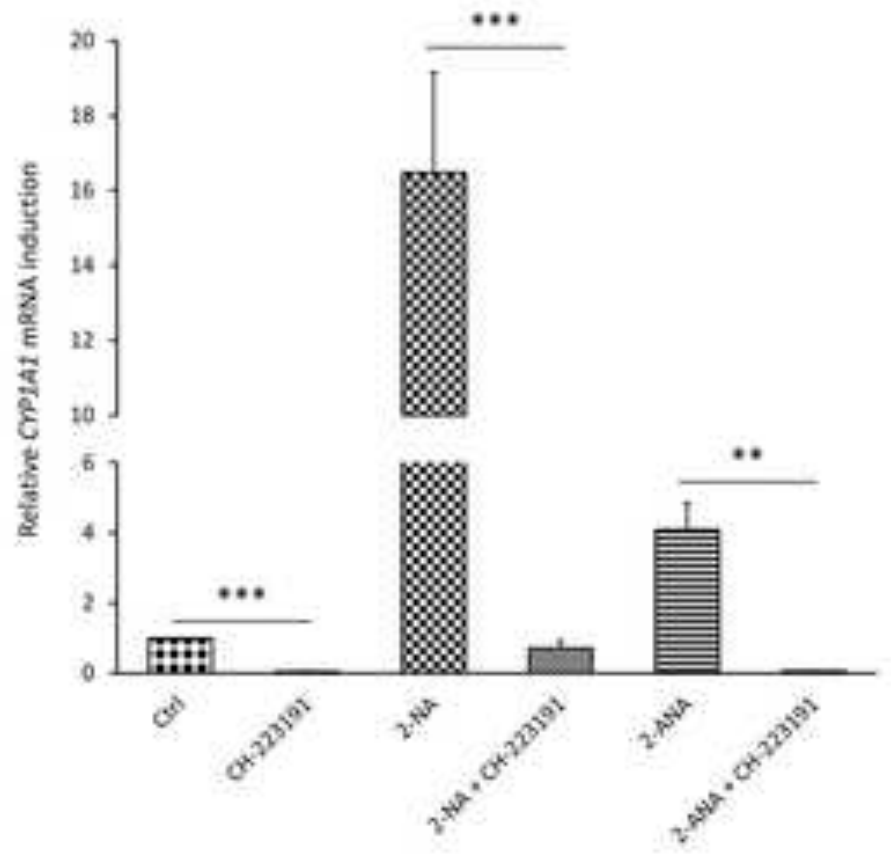

FIGURE 4 
Supplementary Figure 1
Click here to download Supplementary Material: Supplementary figure 1.tiff

列

$\sqrt{3}$
Click here to download Supplementary Material: Supplementary figure 1.tiff

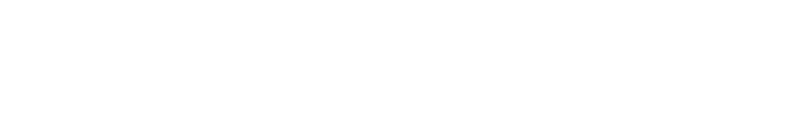

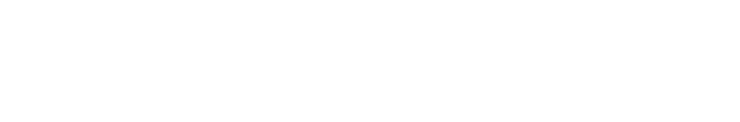
(1) (1)

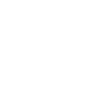

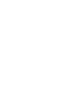

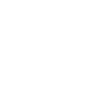

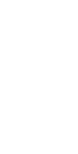

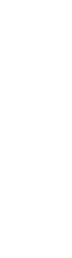


Supplementary Table 1
Click here to download Supplementary Material: Supplementary table 1.doc

Click here to download Supplementary Materia: Supplementary table 1. doc

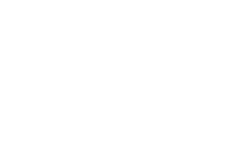
(1) (1) (1)

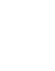

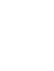
(1) (1) (1) . . . . . . . . . . . . . . . . . 